\section{PODER, LEGITIMAÇÃO E DISTRIBUIÇÃO DE RIQUEZAS ENTRE OS AQUEUS (ILÍADA, CANTO I) ${ }^{1}$}

\author{
Gustavo Frade*
}

Recebido em 24/06/2020

Aprovado em 16/07/2020
*Professor Adjunto de língua e literatura grega, Universidade Federal de Minas Gerais. ghmfrade@gmail.com

RESUMO: Uma interpretação do conflito entre Aquiles e Agamêmnon, no canto I da Iliada, com o objetivo de analisar a lógica do poder por trás da sequência de incidentes que dão início à cólera (mênis) de Aquiles. A disputa, que começa como um embate entre o poder humano de Agamêmnon e o poder divino de Apolo através de seu sacerdote Crises, acaba por revelar toda uma dinâmica do poder humano e do poder divino, em que a capacidade de destruição, os privilégios sociais e a legitimação do poder se integram à ordem cósmica e política de Zeus.

PALAVRAS-CHAVE: Homero; Aquiles; Agamêmnon; honra; cólera.

$$
\begin{array}{r}
\text { POWER, LEGITIMACY, AND WEALTH DISTRIBUTION } \\
\text { AMONG THE ACHAEANS (ILIAD, BOOK I) }
\end{array}
$$

\begin{abstract}
An interpretation of the conflict between Agamemnon and Achilles in Iliad's book I with its main focus on analyzing the logic of power behind the sequence of events that give rise to Achilles' wrath (menis). The dispute, which starts as a clash of Agamemnon's human power against Apollo's divine power, through his priest Chryses, ends up revealing the whole power dynamics of human and divine power, in which the potential for destruction, the social privileges and the legitimacy of power are integrated in Zeus' cosmic and political order.
\end{abstract}

KEYWORDS: Homer; Achilles; Agamemnon; honor; wrath.

\footnotetext{
${ }^{1}$ Versões anteriores deste artigo foram apresentadas nos seguintes eventos: "A Ilíada de Homero e sua recepção na Antiguidade e Modernidade" (USP, 2018), "I Encontro de Pesquisa do LIMES" (UFJF, 2018) e "V Seminário de Estudos Clássicos e Medievais do NEAM” (UFMG, 2019). Recebi, nessas ocasiões e também nos pareceres anônimos, sugestões valiosas e decisivas pelas quais agradeço muito.
} 


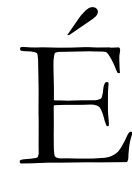

sempre bem lembrado como o principal guerreiro grego da Ilíada é apresentado, no proêmio do poema, por seu impacto negativo no próprio exército: as mortes e dores causadas por sua mênis, cólera que ameaça romper a ordem cósmica e social (I, 1-3). ${ }^{2}$ É também sempre bem lembrado como esse impacto é resultado de um conflito que envolve homens (Aquiles, o filho de Peleu, e Agamêmnon, o filho de Atreu) e deuses (Apolo, por meio do sacerdote Crises, e Zeus, com a articulação de Tétis). ${ }^{3}$ A proposta deste artigo é chamar a atenção para como, logo no início do poema, apresenta-se um conflito entre critérios diferentes para a avaliação do poder dos guerreiros que define cada um desses guerreiros e os enquadra numa estrutura social que responde à ordenação cósmica divina. Compreendo aqui poder, grosso modo, como a capacidade de coerção ou persuasão que, aplicada à tomada de decisões que envolvem um grupo de pessoas, estabelece hierarquias de comando. ${ }^{4}$ Legitimidade, como o reconhecimento social dessa capacidade. ${ }^{5}$

Os dois critérios conflitantes têm em comum estarem fundamentados na capacidade de destruição ${ }^{6}$ e na distribuição privilegiada de sinais de honra, a recompensa ou prêmio

\footnotetext{
${ }^{2}$ Segundo James Redfield (1975, p. 22), a grandeza de um homem, na Iliada, está em sua capacidade de causar efeito sobre os outros. Isso significa que, numa narrativa, as personagens ganham importância por sua capacidade de gerar enredo. Mais do que a história de Aquiles, a Ilíada é a história do efeito desse herói (produto de sua cólera) nos eventos (Redfield, 1975, p. 27). Isso é relacionável ao modo como Leonard Muellner (2011, p. 8 e 26) define mênis: não como simplesmente uma emoção hostil de um indivíduo contra outro, mas como um sentimento intrinsecamente relacionado às ações de uma "sanção cósmica", uma força social com consequências drásticas para a comunidade, com o intuito de "garantir e manter a integridade da ordem mundial". Para Muellner (2011, p. 33), na divisão dos espólios no domínio humano há um aspecto cósmico implícito. Essa posição é também defendida por Jonathan Ready (2007, p. 23): a (re)distribuição reafirma a ordem social e perpetua a ordem cósmica, no caso, o prestígio de Agamêmnon, simbolizado por seu cetro proveniente de Zeus (I, 279-80).

${ }^{3}$ A função de Tétis na Ilíada é rastreada por Laura Slatkin (2011).

${ }^{4}$ Émile Benveniste (1969, p. 71-8) se dedica ao vocabulário do poder na Ilíada. No poema aparece uma série de termos relacionados à força (como bia, is, iskhýs, sthénos, alkêe, dýnamis). Entre eles, destaca alkế e krátos. O primeiro termo, alkée, indica mais especificamente a "fortitude", a coragem de "enfrentar o perigo sem recuar", qualidade fundamental para o guerreiro eficiente. Por sua vez, krátos se aproxima de uma concepção de "poder": é a "superioridade" ou "predomínio" sobre os inimigos ou sobre aqueles com quem se vive. Na guerra, pode ser a superioridade de um guerreiro (IX, 254; XI, 192; XIII, 486; XVI, 524; XVII, 205; XX, 121) ou de um povo (I, 509; VI, 387; XI, 319, 753; XIII, 743; $\mathrm{XV}, 216$; XVI, 623), mas pode também indicar a superioridade na assembleia (XII, 214) e o privilégio pessoal de um chefe (XVI, 54). O verbo kratéo é usado como "ser superior", "trinfar", "exercer o poder", “dominar". No canto I, o adjetivo kraterós, "poderoso", será usado para caracterizar Aquiles por Agamêmnon (I, 178) e Nestor (I, 280).

${ }^{5}$ Compreendo também que a Ilíada representa relações sociais com uma coerência que permite identificar os pressupostos do funcionamento dessas relações, mesmo quando eles não são diretamente explicitados.

${ }^{6}$ Simone Weil (1999 [1940-1], p. 66) entendia que “o verdadeiro herói, assunto e centro da Ilíada é a força", definindo força como aquilo que transforma em coisa toda pessoa que submete e que, "exercida até o limite, transforma numa coisa no sentido mais literal: um cadáver".
} 
(géras) merecido conforme o prestígio ou privilégio (timée) de cada um. ${ }^{7}$ Essa recompensa é atribuída com a distribuição (dasmós) dos recursos obtidos nos saques realizados pelo exército. Tanto a distribuição quanto o privilégio que a orienta estão em jogo nos dois erros de Agamêmnon, que introduzem o recorte narrativo da Ilíada.

O início da desavença está também relacionado à capacidade de destruição divina. A primeira presença divina no poema é a deusa - a Musa, que possibilita o canto a respeito da mênis (I, 1). A segunda é Hades, que recebe em seus domínios as almas (psykhaí, I, 3) dos muitos guerreiros mortos, vítimas da mênis. A terceira é Zeus, cujo desígnio ou deliberação (boulé, I, 5) articula a construção narrativa do poema com a tradição poética e com a experiência do divino. ${ }^{8}$ A quarta é Apolo, que se apresenta como pivô do conflito entre

${ }^{7}$ Pietro Pucci (1998, p. 179) define $\tau$ eń como honra e status privilegiado, incluindo bens materiais
e sinais simbólicos de deferência, como serviços, presentes e gestos de respeito. O produto de um
saque é, num primeiro momento, coletivo (Ready, 2007, p. 27). Conforme Margalit Finkelberg (1998,
p. 20), a distribuição de honra em Homero segue o status social de uma personagem, determinado
por superioridade de nascimento e riqueza. O propósito da (re)distribuição pública é demonstrar esse
status (Ready, p. 4 nota 4). Os cinco estágios da distribuição seriam, segundo Van Wees apud Ready
(2007, p. 4-5): (1) o líder mais proeminente seleciona seu prêmio (géras), (2) dá géras aos homens de
maior status ou de melhor performance, (3) cada líder escolhe sua porção, (4) dá porções para seus
líderes subordinados e (5) cada líder subordinado distribui porções entre seus seguidores. Jonathan
Ready (2007, p. 5-11) indica como na Ilíada um falante, conforme seus objetivos retóricos, pode tratar
a distribuição ou como um ato coletivo ou como um ato do líder: Aquiles fala de Briseida como géras
dada pelos aqueus (I, 162, 276, 392, XVI, 56, XVIII, 444), mas também como ato de Agamêmnon
(IX, 367-8). Ready (2005, p. 19-25, p. 41) também mostra como esse processo, na verdade, inclui
dois modos de aquisição de bens. O guerreiro toma parte numa "transação de curto-prazo", quando
obtém bens no campo de batalha. Depois, os espólios são (re)distribuídos numa "transação de longo-
prazo", que tem o objetivo de perpetuar a ordem social e cósmica. ${ }^{8}$ Embora existam interpretações da Diòs boulé focadas apenas na construção da Ilíada ou em sua relação com a Odisseia (incluídas, por exemplo, entre as cinco interpretações colocadas em questão por James Redfield, 1979, p. 105-7), estudiosos têm se dedicado a pensar a complexidade da boulé como articuladora entre a construção narrativa da própria Ilíada e a tradição poética (como Sheila Murnaghan, 1997, e Morrison, 1997) desde que Kullmann propôs a sua a interpretação, negando a leitura de Aristarco, que identificava o desígnio com a promessa de Zeus a Tétis, e afirmando sua relação com o plano de usar a Guerra de Troia para diminuir o peso da população humana sobre a Terra (1955, p. 173-89). Para Philippe Rousseau (2001, p. 148-52) o plano de Zeus faz com que a parcial derrota dos gregos, decorrente da promessa de Zeus a Tétis, seja o meio pelo qual se efetiva a prenunciada vitória final grega. Ao mesmo tempo, a ausência de um conteúdo explicitado desse plano, no quinto verso, faz com que a sua compreensão dependa da audiência para que se entenda como ela leva à extinção da era dos heróis (2001, p. 152). Joe Wilson (2007, p. 151-3) entende a Diòs boulé como um mecanismo do poeta para, ao mesmo tempo, afirmar sua autoridade através do pertencimento à tradição poética e adaptá-la para sua própria narrativa, de modo que o plano de Zeus seja também o plano do poeta (2007, p. 158). William Allan (2008, p. 205-7) propõe que o entendimento mais amplo possível do termo é algo essencial na performance da canção épica, para enfatizar o poder de Zeus diante dos outros deuses e dos humanos, e permite que a audiência conecte a história da cólera de Aquiles ao contexto cósmico das narrativas épicas caracterizadas pela dominância de Zeus (2008, p. 210-3). A Ilíada parece colocar como eixo da articulação entre o poema e a tradição épica um modo grego arcaico de pensar a experiência do divino na vida humana. 
Aquiles e Agamêmnon (I, 7-10). Quando Crises chega com as insígnias que o identificam como sacerdote de Apolo, ele invoca o deus e oferece um resgate (ápoina) por sua filha, levada por Agamêmnon como prêmio de guerra (I, 14-21). O exército imediatamente concorda que seu pedido seja respeitado (I, 21-22). ${ }^{9}$ Entretanto, ao contrário do interesse geral, ${ }^{10} \mathrm{O}$ que se segue é o primeiro erro de Agamêmnon (I, 26-32):11

Ancião, que eu não tope contigo junto às cavas naus:
não te demores agora nem voltes mais tarde;
receio que o cetro e a grinalda do deus não te protejam.
Não libertarei tua filha; a velhice a pegará antes,
longe da pátria, em nossa propriedade em Argos,
ativa junto ao altar e procurando minha cama. ${ }^{12}$
Para a salvo voltares, não me provoques. ${ }^{13}$

${ }^{9}$ Dean Hammer (1998, p. 340) chama a atenção para a participação pública diante do pedido de Crises, uma vez que o povo "clamou a favor" (epeuphémèsan, I, 22), embora a decisão de Agamêmnon seja contrária a esse clamor. Nathan Greenberg (1993, p. 196-7) considera que Agamêmnon (I, 24) não fica satisfeito com a reação do exército, mas ele mais parece não ter ficado satisfeito com a oferta do sacerdote. Greenberg (1993, p. 197) considera também que a ameaça de Crises é incerta, uma vez que em Homero não se pode contar com a ajuda divina com total garantia. De todo modo, a reação de Agamêmnon parece envolver uma irritação com a ameaça do sacerdote e uma aposta de que Crises não terá influência sobre Apolo (ou, ao menos, a possibilidade da ação de Apolo não se impõe como um temor dominante em sua resposta).

${ }^{10}$ Para David F. Elmer (2013, p. 64-5; 70), Agamêmnon cria uma situação excepcional ou um "estado de exceção" (2013, p. 67) e uma crise distributiva ao rejeitar a vontade coletiva de todos os aqueus (I, 22), e não aceitar ápoina, o "resgate", o que seria o procedimento normal (2013, p. 83-4). Elmer compreende que o funcionamento regular dos processos de tomada de decisão entre os aqueus ocorre pela formação de consensos coletivos. Por isso, a imposição da decisão unilateral de uma figura de poder suspende a normalidade no que diz respeito à tomada de decisões (2013, p. 72). Entretanto, se Agâmemnon subverte um procedimento, essa subversão parece não estar exatamente em ignorar uma vontade coletiva, mas em redistribuir um prêmio já concedido, ainda que esse erro não o invalide socialmente como líder, como veremos na fala de Nestor (II, 275-9). A melhor decisão do líder é considerada aquela que corresponde ao consenso coletivo, mas isso não é o que é posto em prática. ${ }^{11}$ Nathan Greenberg (1993, p. 194), que também reconhece que Agamêmnon avalia mal a influência do sacerdote, chama atenção para o fato de que o narrador mostra esse guerreiro agindo sem nenhuma intervenção de divindade, ou seja, totalmente responsável por sua decisão e ação.

${ }^{12}$ Existem diferentes possibilidades de interpretação do particípio antióósan, que tem um sentido de "indo para" ou "indo para encontrar". Tais possibilidades são bem representadas por diferentes traduções do poema. A opção por "procurando" (como na tradução citada, de Christian Werner, 2018) pode sugerir uma decisão de Criseida. Assim, Agamêmnon parece imaginar que será procurado por interesse da própria mulher escravizada. A tradução de Frederico Lourenço (2013), "e dorme na minha cama", opta por uma neutralidade que não explicita vontade da agente, apesar de direcionar a imagem de dormir para o ato sexual. Haroldo de Campos (2003) opta por "servindo-me ao leito", que explicita a imposição de Agamêmnon sobre a vontade de Criseida.

${ }^{13}$ As traduções citadas aqui têm como base a de Christian Werner (2018) com algumas modificações, exceto quando outra referência for indicada. 
Agamêmnon se vangloria mencionando a condição das vítimas da guerra, ameaça o sacerdote e despreza os sinais de sua relação especial com o deus. ${ }^{14} \mathrm{O}$ erro aqui é, no momento de indignação, não levar em conta a capacidade de destruição do sacerdote (via Apolo) e, consequentemente, avaliar mal seu próprio direito de manter a divisão do produto do saque tal como estava. Percebendo-se impotente diante da destruição causada pelo deus, Agamêmnon tem que reconhecer que é melhor obedecê-lo pelo bem da tropa (I, 116-7). ${ }^{15}$ Por seu contato especial com Apolo (I, 33-43), Crises é capaz de convencê-lo a causar grande mortandade entre os aqueus (I, 50-3).${ }^{16} \mathrm{Na}$ narrativa da Ilíada, essa é a primeira ação

${ }^{14}$ Jasper Griffin e Martin Hammond (1982, p. 131; 139) já interpretavam o embate entre o rei arrogante e o velho humilde como uma introdução no poema do tema das vítimas inocentes da guerra, com a observação de que "a aparente fraqueza de Crises se revela como força real, e o poder de Agamêmnon é reduzido à insignificância” (1982, p. 140). Além disso, Leonard Muellner (2011, p. 97-8) entende que a oferta de Crises - ao se endereçar a todos os aqueus (I, 15) e depois aos dois Atridas (I, 16) - enfatiza a dimensão social da transação, enquanto a resposta de Agamêmnon faz o reverso, agindo em favor dos desejos pessoais desse personagem (I, 24). Christopher Faraone (2015, p. 405) lembra que Aristarco atetiza os versos I, 29-31 por considerar inadequado (ג் a sua cama diante do exército. Faraone se insere numa tradição de interpretação do comportamento de Agamêmnon e de Aquiles no canto I como inconsistentes em relação ao restante do poema. Para ele, a caracterização de Agamêmnon aqui como um rei desrespeitoso para com os deuses seria um dos indícios que indicaria uma origem desse episódio de Crises como um Hino a Apolo autônomo em que Agamêmnon cumpriria o papel de theomákhos (2015, p. 398-405). Interpreto Agamêmnon e Aquiles como personagens que agem de formas diferentes em circunstâncias diferentes, mas sempre com base em como veem a si mesmos e no papel que consideram que devem desempenhar diante do exército aqueu.

${ }^{15}$ Robert Rabel (1988, p. 473-5) lê o episódio de Crises como uma Ilíada em miniatura (com seus temas da desonra e da vingança pela perda de uma mulher), um modelo do tema da vingança bemsucedida e da restituição, com a função de criar expectativas (que serão adiadas no canto IX) de um resultado igualmente favorável para a cólera de Aquiles. Esse autor, assim como Emmet Robbins (2013, p. 74), considera que Aquiles toma o comportamento de Crises como modelo, mas os dois casos podem ser simplesmente a representação do comportamento geral do homem ofendido. Oliver Taplin (1992, p. 54) também vê o conflito com Crises como uma miniatura do conflito com Aquiles: o insulto pela captura de uma mulher (como géras) leva à raiva, que leva a um pedido de intervenção divina como vingança contra Agamêmnon. A diferença é que Criseida será logo restituída. Já Leonard Muellner (2011, p. 116-7), que enfatiza as consequências em grande escala, considerará Aquiles como um "segundo Apolo".

${ }^{16}$ Emmet Robbins (2013, p. 73) interpreta a ação de Apolo como contrapartida pelos favores passados relembrados pelo sacerdote (I, 39-41). Seria nesse caso, em menor escala, semelhante à troca de favores entre Zeus e Tétis (cf. Slatkin, 2011). Robert Rabel (1988, p. 474) interpreta a prece do sacerdote a Apolo como manifestação de fraqueza e dependência de um poder superior. Entretanto, a capacidade de mobilizar esse poder superior me parece, pelo contrário, uma manifestação de poder. O próprio Rabel (1988, p. 476) indica como, na versão da história narrada por Aquiles para Tétis, a fúria é de Crises, não de Apolo. Robbins (2013, p. 74-5) propõe que a diferença entre Aquiles e Crises é que Aquiles não conseguirá renunciar à cólera. 
de um deus em cena e a primeira demonstração do poder dos deuses sobre os humanos. O momento é poeticamente valorizado: ao assumir essa função terrível, Apolo, trazendo a morte, é representado com uma imagem oposta a sua associação ao Sol posterior, no período

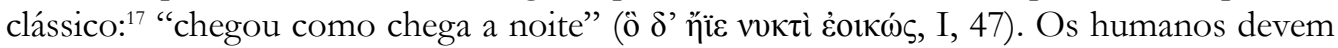
respeitar (azómenoi, I, 21) os deuses e os que lhes são queridos por causa da capacidade que esses têm de matar em grande escala aqueles que contrariam seus interesses.

Curiosamente, a primeira aparição de Aquiles, anunciado nos primeiros versos como a causa de tantas mortes e sofrimentos aos aqueus, ${ }^{18}$ é uma reação às mortes dos guerreiros gregos, incitada por Hera, que se compadecia do exército (I, 53-6). ${ }^{19}$ No décimo dia de peste, Aquiles é quem convoca a assembleia e assume o papel de líder preocupado com o fracasso da guerra, com os motivos das mortes e com as possíveis soluções para a situação (I, 59-67). ${ }^{20}$ Ele até evita mencionar Agamêmnon quando levanta a necessidade de entender

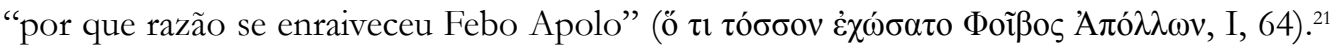
Calcas, o adivinho, com a garantia de que Aquiles o protegeria da possível raiva (khólon, I, 81) de Agamêmnon, ${ }^{22}$ revela a todos as causas e o modo de apaziguar o deus. Assim, indica

${ }^{17}$ Como em Ésquilo, Suplicantes, 212-3, versos destacados por Marcel Detienne (2001, p. 236-7). Walter Burkert (1985, p. 149) e Fritz Graf (2009, p. 121) concordam que Apolo começa a ser associado ao Sol a partir do século V AEC. Numa passagem ressaltada por Pietro Pucci (2018, p. 115), a Ilíada aproveita poeticamente a semelhança sonora entre Phoîbos, "Febo" e phánē, "se fez visível" (XVI, 787-8). Talvez seja um jogo com uma possível etimologia popular. No caso, o que "se fez visível” foi o fim da vida de Pátroclo, de modo que, nessa passagem, o deus exerce de novo uma função relacionada à morte. ${ }^{18}$ Gregory Nagy (1999, p. 69-82) mostra como a Ilíada associa Aquiles ao sofrimento, atribuindo-lhe o papel de causar o sofrimento dos troianos enquanto está em combate ("és o seu maior sofrimento [pêma mégiston]", XXII, 288), e dos aqueus, quando se ausenta ("não te encolerizes! Pois tal foi a dor [ákhos] que se abateu sobre os aqueus”, XVI, 22). Traduções de Frederico Lourenço (2013). Para o próprio Aquiles há sofrimento (ákhos) constante ao longo do poema (IX, 249; XVI, 55; XXIII, 47). Não é preciso que o nome Aquiles tenha uma relação etimológica com láos (exército) e ákhos (sofrimento) como a proposta por Leonard Palmer (1963, p. 79, citada por Nagy). Robert Beekes (2010, p. 183-4) nega essa associação etimológica e confere ao nome origem pré-grega. A Ilíada, entretanto, ao aproximar ákhos e Akhilleús, parece jogar com uma etimologia popular ou poética.

${ }^{19}$ Dean Hammer (1998, p. 340) considera a ação de Hera uma indicação da base carismática da autoridade pública de Aquiles, o herói escolhido para convocar a assembleia. Hammer (1998, p. 346) ainda lembra a excelência política, baseada na performance de atos de fala públicos (os mŷthoi, conforme o estudo de Richard Martin, 1989).

${ }^{20}$ Christian Werner (2004, p. 94) percebe que aqui se valoriza positivamente a proximidade de Aquiles em relação aos deuses, "já que a piedade, mencionada pelo narrador como motivadora da decisão que a deusa põe no espírito do herói é, também, a piedade de Aquiles”.

${ }^{21}$ É, como observa Werner (2004, p. 95), uma posição diplomática.

${ }^{22}$ Agamêmnon tinha acabado de manifestar sua violência contra outro homem com especial relação com os deuses. 
a mênis de Apolo (I, 75), cólera com grande impacto destrutivo sobre os aqueus, ${ }^{23}$ contra o filho de Atreu, devido ao desrespeito com seu sacerdote (I, 94-5). Indica também que essa cólera poderia ser aplacada com a devolução da filha raptada sem a cobrança de um resgate, seguida de uma hecatombe (I, 99).

Nas palavras de Calcas, Agamêmnon é o homem que "chefia a todos os argivos, e os aqueus a ele obedecem" (I, 79). O verbo usado para indicar o exercício da autoridade é kratéo, a efetivação de seu krátos, "poder". ${ }^{24} \mathrm{O}$ exército aqueu é formado por soldados sob comando de chefes locais ou reis (basilêes). ${ }^{25}$ Entre os chefes, por sua vez, Agamêmnon tem uma posição privilegiada de comando. Essa posição poderia estar relacionada ao fato de liderar diretamente o maior contingente de soldados (II, 569-80) e de ter reunido o exército para a expedição contra Troia $(\mathrm{I}, 152-9) .{ }^{26}$ Entretanto, colocado à prova nesse início de

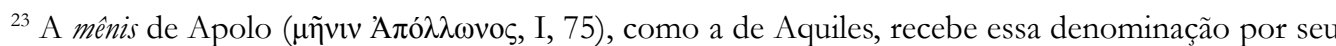
potencial de destruição em massa (cf. Muellner, 1996, 96-111). Além disso, tem também como origem um ato de desrespeito à timé alheia realizado por Agamêmnon (ètímasen, I, 11 e I, 94).

${ }^{24}$ Cf. nota 4.

${ }^{25}$ David F. Elmer (2013, p. 88) chama atenção para o modo como soldados e chefes se distinguem em dois corpos de deliberação coletiva: a assembleia geral (agorê), composta por todo o povo armado (laoí), e o conselho (boulế) de anciãos (gérontes), em que se apresentam os basilêes (II, 50-4). Naoko Yamagata (1997, p. 3-14) propõe que o status, ou função, de basileús faria parte da ordem pública homérica e corresponderia a privilégios, principalmente em termos de presentes (talvez poderíamos acrescentar: uma cota especial nas repartições de espólios de guerra) e responsabilidades (poderíamos adicionar: militares). Esse status seria baseado em riqueza e em seu correspondente prestígio hereditário. Por seu aspecto público, basileús se distinguiria do termo ánax, que seria o soberano ou senhor de um domínio pessoal, um status, ou relação, da ordem privada. O basileús recebe da comunidade, como recompensa ou privilégio, o direito de explorar um lote adicional de terras separadas para esse uso,

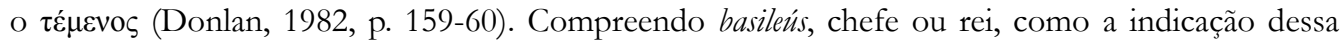
posição social e ánax, senhor ou soberano, como termo que marca, de forma menos específica, o reconhecimento de uma posição elevada dentro de alguma hierarquia. Por isso uma divindade pode ser tratada como ánax, mas somente Zeus e Crono são basilêes.

${ }^{26}$ Oliver Taplin (1992, p. 56-8) observa que não aparece na Ilíada o voto dos pretendentes de Helena a Tindareu, presente em versões posteriores da história da Guerra de Troia. O autor considera que Agamêmnon é coordenador e porta-voz dos aqueus por ter convocado a guerra, mas que não há indícios de que esse seria um "comandante-chefe de uma hierarquia militar". O que se veria seria apenas um sujeito com comando direto sobre os homens que com ele vieram para Troia. Agamêmnon é um basilenis entre outros basilêes (Taplin, 1992, p. 47-8). Sobre as prerrogativas de Agamêmnon, Pietro Pucci (1998, p. 181) observa que ele, como responsável pela expedição, em caso de sucesso terá a glória do momento da vitória (kŷydos, IV, 415), mas, se falhar, dele será o desprezo (II, 285) ou a desonra (IX, 22 = II, 115). Ele cumpre a função de incitar todo o exército aqueu (V, 529 e XI, 153-54, embora Nestor também faça isso, VI, 67-71), de fazer a revista das tropas (epipóntêsis) e de distribuir comida e vinho para todos os outros basilêes. A perspectiva de Pucci (1998, p. 193) é de que "o fato de Agamêmnon dominar tantos homens não é a fonte de seu poder, mas simplesmente uma condição que concede ao poder incondicional de sua palavra consequências maiores”. Aquiles, 
poema, o seu desempenho como líder não é positivo. O próprio intervalo de nove dias (I, 53) entre o início das mortes e a reunião da assembleia pode ser uma marca negativa para sua atuação, ainda mais quando a iniciativa de se mobilizar para resolver a situação vem de outro chefe. Ainda assim, a decisão de devolver Criseida para evitar a morte de mais gente (I, 117) é acertada, mas essa resposta só acontece depois do insulto ao adivinho (I, 106-10) e da manifestação de sua preferência por Criseida em comparação com Clitemnestra, sua esposa legítima (I, 113-20). No canto I, mesmo quando Agamêmnon está tomando uma decisão razoável, sua caracterização é negativa.

O problema é que a exigência de Agamêmnon de ser ressarcido pelo exército para que não fique sem o reconhecimento material que julga adequado (I, 118-9) esbarra no modo como se organiza a posse de riquezas no exército aqueu. Assim que o produto do saque dos territórios inimigos é reunido, para formar o que pode ser chamado de um tesouro público (xynếïa keímena, I, 124), ele é distribuído para donos particulares, de modo que não resta nenhuma reserva comum a partir da qual Agamêmnon possa ser indenizado. ${ }^{27}$ Esse processo é relatado por Aquiles: as riquezas capturadas pelos soldados são levadas a Agamêmnon, que redistribui o montante entre os outros chefes (IX, 330-4). ${ }^{28}$ Organizar essa distribuição é um privilégio consentido pelo exército ao líder, e o prêmio recebido é também um reconhecimento público da honra de cada um diante do exército, de modo que a distribuição é também tratada como um ato coletivo dos aqueus (I, 162).

Duas concepções fundamentais da moralidade guerreira homérica direcionam o segundo erro de Agamêmnon: a ideia de que as riquezas são distribuídas conforme o privilégio ou honra (timế) de cada um, e a importância dada à reputação pessoal, com a correspondência

no entanto, parece reconhecer a posição de Agamêmnon, por ter reunido o exército e por chefiar mais homens. Ao avançarmos nossa leitura aqui, veremos que, como indica Walter Donlan (1979, p. 61), Nestor justifica essa autoridade pelo domínio de Agamêmnon sobre muitos exércitos e por ele ter o cetro cedido por Zeus (IX, 97-102). Além disso, o próprio Agamêmnon inclui como critério de autoridade o fato de ser mais velho (IX, 160). Na síntese de Donlan (1979, p. 52-3), a autoridade - definida como a capacidade reconhecida de dar ordens, tomar decisões e sugerir cursos de ação com a expectativa de ser persuasivo - depende de posse ou de posição social estabelecida (privilégio de dominância dentro de um grupo, que pode envolver sanção divina, idade, riqueza e número de seguidores) ou em habilidade. Ele considera o início da Ilíada como uma disputa entre a autoridade por posição contra a autoridade por habilidade (Donlan, 1979, p. 62). Na Ilíada, Odisseu (II, 203-5) defende explicitamente o benefício de um único comandante (heîs koíranos) em detrimento de um comando múltiplo (polykoiranié).

${ }^{27} \mathrm{O}$ meio principal de aquisição de riqueza móvel nos poemas homéricos é o saque (de animais, homens, mulheres, crianças, objetos de luxo, armamento e metal) para uso, venda ou resgate. O líder bem-sucedido enriquece seus seguidores e recebe uma parcela desproporcional dos espólios, obtendo, assim, riqueza, prestígio e lealdade (Donlan, 1982, p. 142). Além da oferta pela comunidade ou pelo líder depois de um combate ou do saque de uma cidade, há também a possibilidade de obter espólios por outro meio: tomá-los diretamente no campo de batalha, durante o combate ou logo após seu fim (Ready, 2007, p. 3-4).

${ }^{28}$ Cf. a discussão na nota 8 . 
entre a identidade pessoal e a imagem social de um indivíduo. ${ }^{29}$ Como a sua imagem e o seu reconhecimento público são prioridades e como as riquezas já estão distribuídas, o único modo de evitar a desvalorização da timé de um guerreiro exige a desvalorização da timé de outro. ${ }^{30}$ Agamêmnon se vê num ponto tão alto da hierarquia entre os aqueus que propõe uma redistribuição que desonra Aquiles, ainda que o erro anterior tenha sido do próprio Atrida. ${ }^{31} \mathrm{O}$ único poder que o líder dos aqueus reconhece como superior é o poder do deus, o de Aquiles não o preocupa (I, 179-182).

Aquiles, antes de propor que se triplique o butim de Agamêmnon na distribuição do saque na eventual queda de Troia (I, 128), já o trata como "o mais ganancioso de todos os homens" (philokteanôtate pántōn, I, 122). ${ }^{32}$ Essa impressão é ainda amplificada quando o filho de Atreu nega a proposta e exige ser ressarcido com a parte que coube a Aquiles, Ájax ou Odisseu (I, 131-9). Esse momento é significativo por uma série de motivos. A prioridade de Agamêmnon é que a opinião pública sobre ele coincida com sua autoimagem de ser o mais poderoso e importante dos guerreiros aqueus. Para ele é inconcebível aparecer para os outros guerreiros numa posição de subordinação, por mínima que seja. Por isso, num primeiro momento, faz questão de se manter na posição de quem distribui as riquezas saqueadas como bem entende, mesmo que isso signifique realocar os bens já distribuídos. Mesmo a possibilidade de uma futura multiplicação de seu butim com o fim da guerra será ignorada, porque a manutenção pública de sua parte de honra no momento presente é o critério principal para a sua decisão. Agamêmnon insiste nessa aposta porque, além de ter a honra ou imagem pública como critério moral importante, ainda não sentiu os efeitos que a ausência de Aquiles vai causar no seu exército, efeitos que o obrigarão a ressarcir o filho de Peleu.

\footnotetext{
${ }^{29}$ Sobre a imagem social, lembro que é um objetivo do guerreiro homérico obter kléos, reputação ou glória, "aquilo que se escuta sobre alguém" e, mais especificamente, "a gloriosa sobrevivência do herói após sua morte, de modo que a fama do poeta e a glória do herói são inextricavelmente unidas" (Pucci, 1998, p. 210-1). James Redfield (1975, p. 33-4) identifica que kléos é, portanto, a identidade social. A imagem (embora kléos esteja relacionada a "escutar", klýō) que os outros têm de alguém, a partir do que se escuta sobre essa personagem, corresponde ao que se é socialmente.

${ }^{30}$ Walter Donlan (1982, p. 158-61) interpreta a crise de autoridade e liderança na Ilíada como relacionada à questão de quem tem o controle no processo de distribuição. Quando o exército coletivamente oferece um prêmio especial (géras) para o líder ou guerreiro de destaque, o agente da distribuição é o grupo e trata-se, portanto, do compartilhamento de algo devido. Entretanto, quando o líder centraliza a distribuição, esta se torna, na verdade, uma redistribuição de privilégios. Na Ilíada a posição de Agamêmnon será confirmada, mas só depois da indenização de Aquiles (Donlan, 1982, p. 163).

${ }^{31}$ Como observa James Redfield (1975, p. 95-6), Agamêmnon falha em perceber que era uma situação de se render (ao poder do deus) para evitar que a situação piorasse, e seu erro é pedir uma recompensa depois de ressarcir o sacerdote.

32 James Redfield (1975, p. 13) entende Aquiles como um personagem inteligente, mas insensível, que não pensa nas possíveis reações de Agamêmnon e que vai direto ao ponto sem uma estratégia retórica de convencimento. Entretanto, no primeiro momento, com a ação de Hera, Aquiles é sensível ao sofrimento do exército. A situação muda depois que ele se sente desonrado.
} 
Como avalia que seu poder é superior entre os aqueus, Agamêmnon aceita causar o descontentamento de guerreiros que considera menos importantes. Para valorizar sua própria posição, ele pensa logo em três heróis que se destacam: Aquiles e Ájax, como os mais eficientes em combate (II, 768-9), além de Odisseu, o muito astucioso (polýmètis). Para Agamêmnon, nenhuma dessas capacidades rivaliza com o seu poder. Aquiles, no entanto, se dedica a expor para Agamêmnon a inadequação de sua distribuição de riquezas e avaliação de honras merecidas (I, 149-71). ${ }^{33}$ Não há, na Ilíada, uma narrativa detalhada da reunião do exército aqueu para a expedição contra Troia, mas ela aparece sucintamente neste trecho da argumentação de Aquiles: ${ }^{34}$ os aqueus, que, por si só, não têm nenhum problema com os troianos, estão ali seguindo Agamêmnon para obterem honra (timée) para Menelau (I, 152-9). ${ }^{35}$ Para Aquiles, esse papel de articulador da campanha é o que justifica a posição privilegiada de Agamêmnon. ${ }^{36}$ Entretanto, se essa posição possibilita que Agamêmnon tenha

${ }^{33}$ Gregory Nagy (1999, p. 26) observa que nesse início da Ilíada, "durante sua disputa com Aquiles, Agamêmnon também é especificamente descrito como alguém que clama o título de áristos Akhaiôn". Mais especificamente, são Aquiles (I, 91) e Nestor (II, 82) quem se referem a Agamêmnon como quem

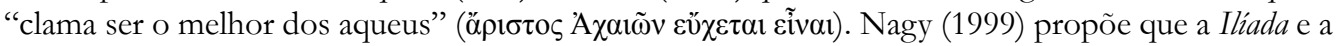
Odisseia contêm em si uma disputa entre dois modelos de herói épico: Aquiles, o herói da força ou violência (biêe e Odisseu, o herói da astúcia (mêtis). São duas alternativas concorrentes para definir o "melhor dos aqueus" (expressão que se refere a Aquiles e Odisseu em Od. 8, 78),

${ }^{34}$ A Ilíada, entretanto, alude, no interior de seu recorte narrativo, aos eventos anteriores e posteriores da Guerra de Troia. A formação do exército, por exemplo, é trazida para o poema no canto II, pela convocação de Agamêmnon para a batalha (II, 441-54), pelos símiles seguintes (II, 455-83), pelo catálogo das naus (II, 484-877), e também pela vistoria das tropas para a retomada da batalha no início do canto IV (220-432).

${ }^{35}$ Apesar dessa crítica de Aquiles, a prática da guerra recebe na Ilíada justificativas materiais e imateriais que fundamentam a ideologia guerreira aristocrática. Para Aquiles, diante da inevitável mortalidade humana, a realização de proezas na Guerra de Troia é a única possibilidade de permanência após a

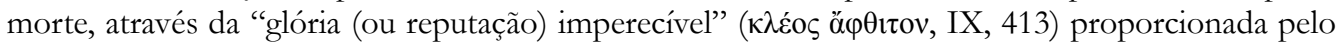
canto dos seus feitos na poesia épica; também Heitor manifesta seu desejo de que "não morra sem esforço e sem fama (akleiôs), mas tendo/ feito algo grande que também os vindouros conheçam" (XXII, 304-5); Odisseu (XIV, 85-7) entende esse modo de vida como parte da identidade aqueia e da ordenação cósmica de Zeus: os guerreiros aqueus são aqueles "a quem Zeus concedeu/ que, da juventude à velhice, arrematássemos/ combates aflitivos até perecermos, cada um de nós”; já Sarpédon (XII, 310-28), considerando, como Aquiles e Heitor, a mortalidade humana, entende que se destacar no combate é o meio de se obter "uma melhor qualidade desta sua única vida, traduzida em bens, boa comida e reconhecimento público, e implicando obviamente o ato mesmo do risco de tudo perder" morrendo no combate (Assunção, 2008, p. 8-9).

${ }^{36}$ Como observa Pietro Pucci (1998, p. 184-5), o pacto entre os gregos é um pacto de amizade, baseado em proporcionar kháris (alegria e gratidão) a Agamêmnon e obter honra para ele e Menelau, embora Aquiles o mencione para enfatizar a sua marginalidade e a sua solidão. Pucci (1998, p. 182-3) ainda prefere interpretar que o poderio militar superior de Agamêmnon (I, 281) não pode ser o único motivo de sua posição de destaque, porque ele nunca teme uma coalizão de forças contra si. Sua sugestão é de que ele é o líder por ser reconhecido socialmente como líder, com autoridade garantida sobre a comunidade. Veremos que isso se sustenta pela legitimação do poder de Agamêmnon como proveniente de Zeus. 
a maior parte das riquezas distribuídas ou que controle a sua distribuição, para Aquiles ela não corresponde à recompensa pelos esforços ou pela eficiência na guerra. A ganância e o egoísmo de Agamêmnon o impedem de valorizar devidamente seu poder de destruição (I, 165-8):

contudo, a maior parte da guerra encapelada meus braços realizam, e se ocorre uma partilha (dasmós), tua recompensa (géras) é muito maior, e levo uma pequena e querida na volta às naus, quando lutei até a exaustão.

Para Aquiles, a divisão do esforço não corresponde à divisão das riquezas obtidas por meio desse esforço, com o detalhe de que o esforço em questão é a guerra, e a obtenção de riquezas, na verdade, é o saque de qualquer objeto de valor e o rapto de mulheres. ${ }^{37} \mathrm{O}$ cansaço de Aquiles e sua maior eficiência em combate, de todo modo, não são compensados, e as riquezas são acumuladas por Agamêmnon. Esses argumentos voltam a aparecer na resposta de Aquiles a Odisseu na embaixada do canto IX, 318-333: Aquiles, saqueador de vinte e três cidades, com o exército e a frota dos aqueus ajunta grande quantidade de bens para o Atrida que apenas distribui pouco e fica com muito sem se arriscar. Trata-se de uma alegação exagerada de Aquiles, uma vez que Agamêmnon também luta (V, 38-40, 533-40) e chega a arriscar a sua vida (XI, 153-274), mas revela a sua indignação com a posição que tem no exército.

Isso revela que os dois chefes têm critérios diferentes e concorrentes para avaliar o mérito e o poder. A crítica de Aquiles tem a mesma fundamentação na ideologia guerreira aristocrática compartilhada por Agamêmnon, mas questiona diretamente quem tem a maior capacidade de destruição e, portanto, quem merece ser mais honrado e ter prioridade na distribuição de riquezas. Trata-se, portanto, de um questionamento da própria posição privilegiada de Agamêmnon. Para Aquiles, se Agamêmnon inicialmente é quem "agora

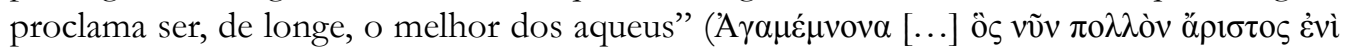

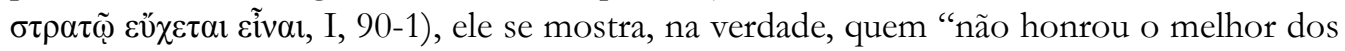

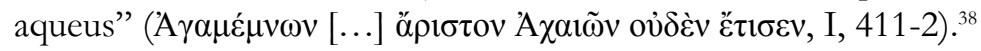

$\mathrm{Na}$ continuação da discussão, Agamêmnon deixa sua perspectiva bem clara para Aquiles ao exigir a entrega de Briseida (I, 184-7):

[...] vou buscar Briseida bela-face, tua recompensa (géras), ${ }^{39}$ eu mesmo indo à cabana, para bem saberes quão superior a ti sou eu, e que outros se apavorem de se crer igual a mim e de rivalizar face a face.

\footnotetext{
${ }^{37}$ Ao longo da Ilíada, várias informações são apresentadas sobre as cidades saqueadas pelos aqueus e os prisioneiros capturados (Robbins, 2013, p. 81; Rego, 2020).

38 Tersites também expressará a sua opinião de que Aquiles é “um homem muito melhor” ( $\mu \varepsilon^{\gamma}$ ' à $\left.\mu \varepsilon^{i v o v \alpha} \varphi \tilde{\omega} \tau \alpha\right)$ e mais forte que Agamêmnon, o acumulador de riquezas que desvaloriza a contribuição dos demais (II, 225-42).

${ }^{39}$ Frederico Lourenço (2013) traduz como "essa que te calhou como prêmio".
} 
Agamêmnon se declara o mais forte (phérteros) entre os dois e, mais do que isso, superior a todos os outros aqueus..$^{40}$ Aquiles, porém, interpreta a questão de forma diferente. Persuadido por Atena, enviada por Hera, a não tomar a decisão de matar o líder dos aqueus e a aceitar a previsão de riqueza multiplicada no futuro, em troca de restringir sua agressão a xingamentos (I, 188-218), ${ }^{41}$, Aquiles apresenta uma crítica feroz ao comportamento de Agamêmnon (I, 225-33): é um covarde que não participa da guerra, toma indevidamente as posses dos que questionam suas ações publicamente e só se mantém em posição de

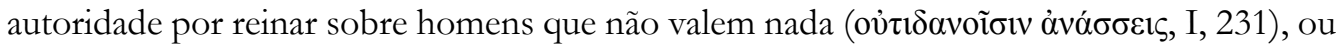
seja, que toleram indevidamente a covardia e a injustiça de sua acumulação e má distribuição de riquezas. ${ }^{42}$

Recorrentemente, a ação de Agamêmnon é avaliada nas falas de Aquiles e na de Atena com os termos morais que indicam a transgressão dos limites sociais: byperoplía (I, 205), hýbris (I, 214), o verbo lōbáomai (lōbếsaio, I, 232). Quando Aquiles diz que Agamêmnon é um chefe (basileús) "devorador de seu povo" (démobóros, I, 231), ${ }^{43}$ ele escolhe uma imagem que acrescenta à transgressão um aspecto material, o consumo das riquezas produzidas ou reunidas pelo povo. Não está distante da imagem de Hesíodo, que questiona a justiça das decisões desses chefes classificando-os como "devoradores de presentes" (dörophágous, Trabalhos e dias, 39), embora não assuma a perspectiva do trabalhador rural: trata-se de um chefe insultando outro chefe. A imagem também aproxima Agamêmnon do grupo de

\footnotetext{
${ }^{40}$ Walter Donlan (1971, p. 111) apresenta outra interpretação: para ele, as ameaças de violência mascaram a insegurança de Agamêmnon.

${ }^{41}$ Como observa Oliver Taplin (1992, p. 65), Atena confirma para Aquiles seu futuro sucesso na disputa e classifica o comportamento de Agamêmnon como býbris. Sua posição superior no que diz respeito à força é depois confirmada por Tétis. Ao mesmo tempo, como argumentou Pietro Pucci (1998, p. 194-8), essa cena, que mostra a intimidade especial de Aquiles com deuses, mostra também como o poeta faz coincidir o plano narrativo e o plano teológico, ou seja, através da ação das deusas ela põe em ação os desígnios de Zeus, poupando a vida de Agamêmnon e preparando a futura morte de Aquiles.

${ }^{42}$ Leonard Muellner (2011, p. 106) indica que Agamêmnon insulta Aquiles por ver sua autoridade questionada por um herói socialmente inferior. Aquiles insulta Agamêmnon por seu desrespeito à distribuição que sustenta a hierarquia social dos aqueus. A timé (prestígio) de Aquiles é desrespeitada, sendo que a própria guerra objetiva restaurar a timé dos Atridas. Margaret Graver (1995, p. 44-5) informa que os escoliastas associam o uso do cachorro como metáfora com o sentido de falta de vergonha (anaidés), mas o sentido pode estar também relacionado à ganância e voracidade (Graver, 1995, p. 46-9), o que não está longe do uso, na Odisseia, de kýnteron ("mais cachorro") para caracterizar o estômago (gastér) por sua necessidade voraz de ser recorrentemente preenchido. Ainda é empregado, nas palavras de Teodoro Assunção (2003/4, p. 58-9), "para a animalidade criminosa da antropofagia e indiretamente para a animalidade lúbrica de uniões sexuais fora do quadro normativo do casamento". ${ }^{43}$ Pierre Chantraine (1999, p. 175) e Robert Beekes (2010, p. 214) concordam quanto a esse sentido

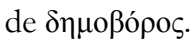


transgressores da Odisseia, os pretendentes, que consomem o patrimônio de Odisseu sem contrapartida e sem permissão. ${ }^{44}$

É notável como são fundamentais para o guerreiro homérico alguns valores imateriais, como a excelência em combate, a habilidade nos discursos e a permanência na memória cultural dos feitos heroicos enquanto objeto de canto nas narrativas épicas. Entretanto eles parecem indissociáveis dos elementos materiais que são, ao mesmo tempo, privilégios de uma classe que detém as riquezas, inclusive, como signos sociais do reconhecimento público daqueles valores imateriais. ${ }^{45}$ Essa associação é também observada por Platão. Na República, 390e, ele faz seu Sócrates criticar o comportamento philokhrématon, “ávido por riquezas”, do guerreiro homérico. Platão menciona, ainda que sem contextualização, o conselho de Fênix a Aquiles no canto IX (515-26): o herói deveria socorrer os aqueus, uma vez que está recebendo presentes; se não estivesse, não deveria amenizar a sua cólera (mênis). ${ }^{46}$ Aquiles, quando reclama da distribuição (dasmós, I, 166), atribui até um valor afetivo àquela parte do

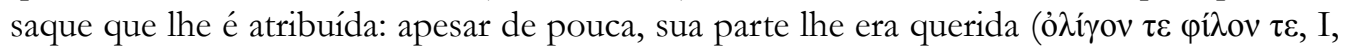
167). Isso é especialmente significativo quando essa parte inclui uma mulher escravizada, como Briseida.

Essa discussão termina com a confirmação da autoimagem de Agamêmnon como o mais poderoso entre os aqueus, que obtém Briseida como compensação (I, 318-48). ${ }^{47} \mathrm{Se}$ considerarmos o caráter público da disputa entre os dois chefes, o narrador não informa o posicionamento dos aqueus em geral, mas apresenta a interferência de Nestor, que revela tanto qual é a tensão básica no que diz respeito ao exercício do poder entre os aqueus quanto o critério definitivo para a sua resolução.

$\mathrm{O}$ ancião intervém depois que Aquiles anuncia sua retirada da guerra e, como expressão de sua raiva e do desprezo pela ordem de Agamêmnon, atira no chão o cetro

\footnotetext{
${ }^{44}$ Tema que discuto em minha tese de 2017.

${ }^{45}$ Para Walter Donlan (1971, p. 110-1) a crítica de Aquiles faz com que Agamêmnon pareça puramente materialista; entretanto, devolver Criseida sem compensação seria admitir sua culpa pela peste. Mesmo dessa maneira, esses valores materiais e imateriais estariam também intrincados. O caráter inseparável da honra de suas manifestações materiais (como comida de melhor qualidade, presentes e posses) é observado por Jasper Griffin (1980, p. 14-5) e sintetizado por Margalit Finkelberg (1998, p. 16) e pode ser confirmado pelo discurso de Sarpédon (XII, 310-28) mencionado aqui na nota 35.

${ }^{46}$ O Sócrates platônico menciona ainda a decisão de Aquiles no canto XXIV, de "devolver o cadáver [de Heitor] depois de receber o resgate (timế), e não aceitar de outro modo". Nesse caso, entretanto, não há uma exigência de Aquiles. É o próprio Zeus (XXIV, 117-9) quem, via Íris, comunica a Príamo que leve presentes e, via Tétis, comunica a Aquiles que os aceite (XXIV, 137-140). Príamo oferece os presentes (XXIV, 502 e 555), que têm seu valor reconhecido por Aquiles, o qual, por sua vez, separará parte como oferenda a Pátroclo (XXIV, 592-5).

${ }^{47}$ Pietro Pucci (1998, p. 186) sugere que, com o silêncio, a assembleia concorda que é impróprio o chefe ficar sem seu prêmio. Entretanto, o narrador nada informa sobre a reação do exército. Não há menção ao silêncio, como acontece, por exemplo, quando menciona explicitamente "e todos, atentos,

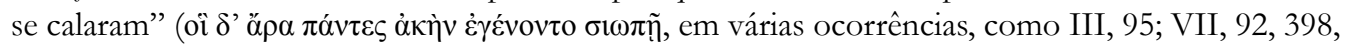
427; VIII, 28; IX, 29, 430, 693 entre outras).
} 
(I, 245), o objeto que sinaliza a autoridade de quem fala. Nestor é apresentado como grande orador (I, 248-50), como um sábio com experiência sobre as coisas humanas (I, 251-2) e como alguém bem-intencionado (I, 253). A introdução para seu bom conselho (que acaba ignorado) invoca o sentimento de união dos aqueus contra os troianos (I, 254-8) e contém o seu tema característico: as histórias do passado, a força dos homens daquela época e os seus próprios feitos de juventude (I, 259-74). É essa experiência o que sustenta a autoridade de sua fala entre os guerreiros. Seu conselho prático é uma tentativa de restabelecer tudo como era antes: Agamêmnon, o detentor de maior poder (phérteros, I, 280-1) ${ }^{48}$ não deve tirar Briseida de Aquiles (I, 275-6), que, por sua vez, ainda que mais poderoso individualmente por ser filho de uma deusa (karterós, I, 280), deve reconhecer a autoridade de Agamêmnon e continuar na guerra (I, 277-84).

Isso significa que a autoridade privilegiada de Agamêmnon não pode ser colocada em questão, ao mesmo tempo em que a sua decisão de tomar Briseida de Aquiles é um erro, porque os "filhos dos aqueus" já haviam lhe concedido o prêmio (I, 275-6). ${ }^{49} \mathrm{O}$ líder age melhor quando contempla o conselho de outros aqueus e o desejo coletivo, mas a sua posição legítima de liderança não é invalidada caso considere apenas as suas próprias circunstâncias e cometa erros. Essa posição se sustenta por uma relação com a divindade.

O poder como concessão divina aparece, primeiramente, aplicado por Agamêmnon à força de Aquiles: "se és excepcionalmente possante (karterós), é porque um deus tal te concedeu" (I, 178). ${ }^{50}$ Essa condição o tornava detestável ("de todos os reis criados por Zeus, és para mim o mais odioso", I, 176) pelo excessivo gosto por combates em que pode predominar sem um rival à altura. Agamêmnon sustenta a sua posição reconhecendo em Aquiles uma ameaça à hierarquia do exército. Por isso, Briseida deve ser tomada para servir de exemplo a qualquer outro que ouse questionar a sua superioridade (I, 184-7), e a ambição de Aquiles deve ser controlada (I, 287-91):

\footnotetext{
${ }^{48}$ Pietro Pucci (1998, p. 189) considera que, ao dizer que é melhor que Aquiles, Agamêmnon, que ainda tem a consideração dos aqueus, está apenas atestando um fato que a assembleia reconhece.

${ }^{49}$ Em I, 275, o modo como Nestor se dirige a Agamêmnon pode ser entendido de duas maneiras,

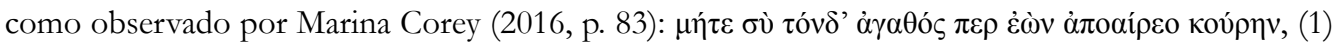
"nem tu, embora valoroso, dele tomes a moça" (interpretando ả $\gamma \alpha \theta$ ó $\varsigma \varepsilon \rho \rho \dot{\varepsilon} \omega े v$ com sentido concessivo, como fazem Christian Werner, Frederico Lourenço e Haroldo de Campos) ou (2) "nem tu, uma vez que és valoroso, dele tomes a moça” (interpretando ỏ $\gamma \alpha \theta$ ó $\varsigma \pi \varepsilon \rho \dot{\varepsilon} \grave{\omega} v$ com sentido causativo). Nas duas interpretações, contudo, Nestor tenta restabelecer a ordem recuperando a moça para Aquiles ao mesmo tempo em que tenta valorizar Agamêmnon como um homem agathós (um homem que corresponde à excelência marcial e social do guerreiro, a aretê) com duas possibilidades de nuances diferentes: numa interpretação (1), Nestor reconhece que o esperado seria que um homem agathós tivesse seu géras, mas que, nesse contexto, Agamêmnon deveria ceder, o que não invalidaria sua posição de agathós; na outra (2), abrir mão do géras aparece como um ato de diplomacia digno e esperado do homem agathós. ${ }^{50}$ Cito aqui I, 178 e depois o I, 176, na tradução de Frederico Lourenço (2013).
} 
Mas esse homem quer estar acima de todos os outros, quer ter poder (kratéein) sobre todos, ser senhor (anássein) de todos e a todos dar ordens (sémaínein), e não creio que será obedecido. Se os deuses sempre vivos o fizeram lanceiro, por isso o incumbem de discursar insultos?

Essa é a tensão construída desde a primeira menção a Agamêmnon no poema (I, 7), caracterizado como "senhor de homens" (ánax andrôn) em oposição ao divino (dîos) Aquiles.

Acontece que, socialmente e narrativamente, a posição de Agamêmnon, como a de Aquiles, também é justificada por uma relação especial com a divindade. ${ }^{51}$ Nestor, ao avaliar o poder do filho de Atreu, considera, além do comando sobre maior número de homens, uma autoridade conferida por Zeus (I, 277-9):

Nem tu, filho de Peleu, queiras rivalizar com um rei (basileús)

opondo forças, já que nunca recebe honra (timé) igual

o rei (basileús) porta-cetro a quem Zeus deu o triunfo (kŷdos).

Tradicionalmente traduzido como "glória", kŷdos reúne em seu sentido as noções de vitória, brilho e favor dos deuses. ${ }^{52}$ Em contextos de batalha, ky $y$ dos indica na maior parte de suas ocorrências o triunfo brilhante do guerreiro vencedor, concedido pela divindade no momento decisivo. ${ }^{53}$ Esse triunfo parece fundamentar a prevalência do privilégio (timế) daquele que o recebe e, consequentemente, atribuir autoridade como uma concessão de Zeus. Os usos desse termo não diretamente relacionados ao combate são mais raros, mas esta não é a única ocorrência. Ele aparece junto com a timée e com os privilégios materiais dos chefes também nesta fala de Menelau, (XVII, 248-51):

Amigos, líderes e dirigentes dos argivos, os que junto ao Atrida Agamêmnon e a Menelau bebem o que vem do povo e comandam as tropas, e sua timếe kŷydos vêm de Zeus.

Aparece ainda quando Zeus envia Tétis com a ordem de que Aquiles entregue o cadáver de Heitor a Príamo em troca de um resgate, para que o corpo não seja roubado por Hermes, instigado por outros deuses (XXIV, 104-19). Dessa maneira, Zeus afirma que concede a Aquiles esse kŷdos (XXIV, 110), o triunfo glorioso e incontestável sobre o melhor

\footnotetext{
${ }^{51}$ Aliás, como observa Emmet Robbins (2013, p. 73), tanto Agamêmnon quanto Aquiles esperam ser honrados por Zeus (I, 175), mas, nesse conflito, Zeus só pode honrar um, e Aquiles tem a influência de sua mãe sobre Zeus para estabelecer o privilégio de sua "honra e afeição".

${ }^{52}$ Embora Pietro Pucci (2018, p. 82) observe que é incerto o quão essencial e intensa é essa ideia de brilho.

${ }^{53}$ Conforme Pucci (1998, p. 206): "brilho da glória", "favor do deus", "brilho da vitória nas batalhas". Essas noções formam o sentido de kŷdos. Sua presença é de curta duração (Pucci, 2018, p. 248).
} 
dos troianos. ${ }^{54} \mathrm{~A}$ princípio, pode parecer deslocado o uso desse conceito para justificar socialmente as decisões e ações de uma figura de poder. Esse uso revela, entretanto, que o poder se manifesta e se exerce intrinsecamente como produto de uma disputa, e a resolução dessa disputa é diretamente associada a Zeus. ${ }^{55}$ Não é por acaso que os basilêes recebem a caracterização formular "criados por Zeus", ${ }^{56}$ dita por Agamêmnon em I, 176, nem é por acaso que os chefes Odisseu e Nestor sejam chamados de "grande kŷydos dos aqueus". ${ }^{57}$

Há ainda outra associação direta com os espaços de disputa pelo poder: além do combate (mákhē), apenas a assembleia (agorê) é caracterizada como kydiáneira, "que proporciona kŷdos aos homens". ${ }^{58}$ Nesse ambiente, se o cetro sinaliza a autoridade de quem fala, o de Agamêmnon é ainda especial, porque foi feito por Hefesto e dado a Zeus, antes de ser repassado a Hermes, a Pélops, a Tiestes e, por fim, a Agamêmnon (II, 1028), representando materialmente a continuidade entre a autoridade de Agamêmnon e a autoridade divina.

Nestor se refere a Agamêmnon na assembleia do canto IX com o superlativo kŷdistos, "o mais glorioso", "O muitíssimo agraciado com kŷdos", 59 o "senhor de homens" (ánax andrôn, IX, 96), que recebeu de Zeus o cetro e a thémis (IX, 98-9), a justiça ou seu exercício como um ato ou prática que traz para a esfera humana a ordenação da esfera divina. Cetro e thémis são também os dons recebidos pelo basilenis no discurso de Odisseu em defesa do comando de um único homem (II, 206) ${ }^{60}$ Portanto, o poder dos basilêes entre os humanos é uma concessão divina, e também o poder de Agamêmnon entre os basilêes, segundo Nestor

\footnotetext{
${ }^{54}$ Claude Brügger (2017, p. 62) entende a entrega do corpo com a aceitação de presentes como um modo de preservar socialmente a honra de Aquiles.

${ }^{55}$ É sobretudo Zeus quem concede kŷdos, mas, em contexto de combate, é resultado da ação de outros deuses, como Apolo (XV, 327; XVI, 730; XXI, 596; XXII, 18, em que Aquiles diz que Apolo lhe impede de obter kŷdos) e Atena (V, 260; XXII, 217, ação conjunta com Aquiles para levar kŷdos para os aqueus; XXIII, 400). Ao mesmo tempo, é algo que um guerreiro obtém entre os homens (IX, 303; XVII, 287) e que um combatente morto lhe concede (XV, 644). As ocorrências em que parte de Zeus são bem mais abundantes. Alguns exemplos: V, 33, 225; VII, 205; VIII, 141, 176, 216; XI, 79, 300; XII, 255, 407, 437; XIV, 358, 596, 602; XVI, 88, 241; XVII, 566; XVIII, 294; XIX, 204; XXI, 570.

${ }^{56}$ Variação de $\delta 10 \tau \rho \varepsilon \varphi \varepsilon ́ \varepsilon \varsigma ~ \beta \alpha \sigma i \lambda \tilde{\eta} \varepsilon \varsigma$ (I, 176; II, 98, 196, 445; IV, 338, 464; XIV, 27; XXIV, 803), no genitivo singular e plural e no nominativo plural, sempre no fim do verso.

${ }^{57}$ Nestor: X, 87, 555; XI, 511; XIV, 42. Odisseu: X, 544. A atribuição desse aposto formular pode estar relacionada a uma especial associação desses dois chefes à vitória dos aqueus.

${ }^{58}$ Como aponta Pucci (1998, p. 207). A assembleia é assim caracterizada em I, 490. O combate em IV, 225; XII, 325; XIII, 270 e XIV, 155. Em todas as ocorrências, o epíteto aparece na posição final do verso.

${ }^{59}$ Pietro Pucci (1998, p. 189-90) observa que Zeus e Agamêmnon usam expressões semelhantes para afirmar autoridade entre homens e deuses (I, 185-7 e XV, 167; I, 180-81 = XV, 106-7; I, 186 e

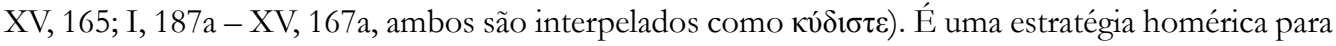
integrar o poder dos líderes humanos à ordem de Zeus.

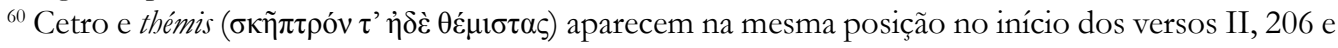
IX, 99, como síntese da legitimação e do exercício de poder concedidos por Zeus aos chefes.
} 
(I, 277-9). O narrador revela essa ligação para os ouvintes ou leitores através do cetro, e, entre as personagens, são os outros chefes, Nestor e Odisseu, comprometidos com o glorioso triunfo (kŷjos) dos aqueus, quem defendem diante dos soldados essa integração da hierarquia do exército à ordenação cósmica divina, sob a autoridade de si mesmos como basilêes, e sob o comando superior de Agamêmnon.

Embora Aquiles admita que, mesmo para ele, é difícil lutar sem a participação ativa dos demais aqueus $(\mathrm{XX}, 356-7),{ }^{61}$ a narrativa da Ilíada confirmará o seu desempenho como guerreiro, único e inigualável entre os humanos. Ao mesmo tempo, ela confirma e reabilita Agamêmnon como comandante com a reintegração de Aquiles ao exército aqueu. No canto IX, 115-61, o próprio Agamêmnon precisa aceitar a superioridade militar de Aquiles, embora encerre a sua fala defendendo sua posição pública como "mais chefe" (basileúteros) e "mais velho" (progenésteros). ${ }^{62} \mathrm{O}$ poema mostrará, entre os cantos VIII e XVI, o estrago que a ausência de Aquiles causa aos gregos e, a partir daí, o estrago que sua presença causa aos troianos. Todo esse poder destrutivo, contudo, subordina-se à mesma organização cósmica de Zeus que concede o privilégio especial para Agamêmnon.

Não deixa de ser notável como o próprio Aquiles - que a princípio aparece, por ação de Hera, como o protetor do povo que sofre pelas más decisões de Agamêmnon aceita ou mesmo causa o sofrimento desse mesmo povo quando é ele quem se vê desonrado publicamente (I, 241). Também é notável como as riquezas materiais estão associadas aos fundamentos da moralidade do guerreiro aristocrata homérico, seja como privilégio material de uma classe dominante, diretamente relacionada à percepção pública de seu valor, seja como representação simbólica de seu poder.$^{63}$ Nessa dinâmica entre capacidade de destruição, distribuição de riquezas, honra, reputação e legitimação divina se revela o entendimento de poder na Iliada.

\footnotetext{
${ }^{61}$ Em geral, a massa de guerreiros anônimos aparece na Ilíada mais como plateia que julga os feitos dignos de reconhecimento e memória dos heróis principais, feitos realizados, portanto, diante do público e que faz parte das justificativas para a posição de privilégio desses heróis, como demonstrado por Gustavo Oliveira (2010).

${ }^{62}$ Como observa Rainer Friedrich (2011, p. 280), é, ao mesmo tempo, uma admissão de derrota na contenda com Aquiles e uma tentativa de manter a sua posição entre os aqueus. Exigir que Aquiles se submeta a si (IX, 158-61) cancela a concessão inicial (IX, 115-20): por isso Odisseu, cuidadoso, omite para Aquiles, na embaixada (IX, 225-306), esses dois trechos da fala de Agamêmnon (Friedrich, 2011, p. 280-1). Quanto a ser mais velho, é também uma justificativa para a hierarquia superior de Zeus sobre Possêidon, paralela à maior força (XIII, 355 e XV, 181-3). Em XIII, 355 ser mais velho acompanha um maior conhecimento, também em XIX, 219; XXI, 440 e XXIII, 312, como indica Pietro Pucci (2018, p. 196, nota 99).

${ }^{63}$ Robert Rabel (1988, p. 478) chama atenção para como nenhuma das vítimas de Agamêmnon, que desonrou um mortal e ofendeu um deus, separa a questão da honra da questão da compensação material.
} 


\section{REFERÊNCIAS}

ALLAN, William. Performing the Will of Zeus: The $\Delta$ iò $\varsigma \beta 0 v \lambda \eta$ and the scope of early Greek epic. In REVERMANN, Martin; WILSON, Peter (eds.). Performance, iconography, reception: Studies in honour of Oliver Taplin. Oxford: Oxford University Press, 2008.

ASSUNÇÃO, Teodoro Rennó. Nota sobre o y $\alpha \sigma \tau \eta \dot{\rho}$ funesto e ultra-cão na Odisseia. Kleos, n. 7/8, p. 55-69, 2003/4.

ASSUNÇÃO, Teodoro Rennó. Boa comida em banquetes como razão para arriscar a vida: o discurso de Sarpédon a Glauco (Ilíada XII 310-328). Nuntius Antiquus, n. 1, p. 1-17, 2008.

BEEKES, Robert. Etymological dictionary of Greek. Leiden: Brill, 2010.

BURKERT, Walter. Greek religion. Tradução por John Raffan. Cambridge: Harvard University Press, 1985.

BRÜGGER, Claude. Homer's Iliad: The Basel Commentary, Book XXIV. Translated by Benjamin W. Millis and Sara Strack. Edited by Joachim Latacz, Anton Bierl and S. Douglas Olson. Berlin; Boston: De Gruyter, 2017.

CAMPOS, Haroldo de. Ilíada de Homero. Introdução e organização de Trajano Vieira. São Paulo: Arx, 2003.

CHANTRAINE, Pierre. Dictionnaire étymologique de la langue grecque. Paris: Klincksieck, 1999.

CORAY, Marina. Homer's Iliad: The Basel Commentary, Book XIX. Translated by Benjamin W. Millis and Sara Strack. Edited by Joachim Latacz, Anton Bierl and S. Douglas Olson. Berlin; Boston: De Gruyter, 2016.

DETIENNE, Marcel. Apolo con el cuchillo en la mano. Una aproximación experimental al politeísmo griego. Traducción: Mar Llinares García. Madrid: Ediciones Akal, 2001.

DONLAN, Walter. Homer's Agamemnon. The Classical World, v. 65, n. 4, p. 109-15, 1971.

DONLAN, Walter. The structure of authority in the Iliad. Arethusa, v. 12, n. 1, p. 51-70, 1979.

DONLAN, Walter. Reciprocities in Homer. The Classical World, v. 75, n. 3, p. 137-75, 1982.

ELMER, David F. The Poetics of Consent: Collective Decision Making and the Iliad. Baltimore: The Johns Hopkins University Press, 2013.

FARAONE, Christopher A. On the eve of epic: did the Chryses episode in Iliad I begin its life as a separate Homeric Hymn? In: KLIGER, Ilya e MASLOV Boris (eds.). Persistent Forms: Explorations in Historical Poetics. Nova York: Fordham University Press, 2015.

FINKELBERG, Margalit. Patterns of human error in Homer. The Journal of Hellenic Studies, v. 115, p. 15-28, 1995.

FINKELBERG, Margalit. Time and Arete in Homer. The Classical Quarterly. New series, v. 48, n. 1, p. 14-28, 1998. 
FRADE, Gustavo Henrique Montes. Pretendentes e profecias ou a experiência da indeterminação na Odisseia. Tese (Doutorado em Literaturas Clássicas e Medievais) - Programa de Pósgraduação em Estudos Literários. Faculdade de Letras, Universidade Federal de Minas Gerais, Belo Horizonte, 2017.

FRIEDRICH, Rainer. Odysseus and Achillleus in the Iliad. Hidden hermeneutic horror in readings of the Presbeia. Hermes, v. 139, n. 3, p. 271-90, 2011.

GRAF, Fritz. Apollo. London: Routledge, 2009.

GRAVER, Margaret. Dog-Helen and Homeric insult. Classical Antiquity, v. 14, n. 1, p. 41-61, 1995.

GREENBERG, Nathan A. The attitude of Agamemnon. The Classical World, v. 86, n. 3, p. 193-205, 1993.

GRIFFIN, Jasper. Homer on life and death. Oxford: Oxford University Press, 1980.

GRIFFIN, Jasper; HAMMOND, Martin. Critical appreciations VI. Homer, Iliad 1.1-52. Greece \& Rome, v. 29, n. 2, p. 126-42, 1982.

HAMMER, Dean. Homer, tyranny, and democracy. Greek, Roman, and Byzantine Studies, v. 39, n. 4, p. 331-60, 1998.

HOMERI Ilias. Edição de T. W. Allen. Oxford: Clarendon Press, 1931.

HOMERO. Ilíada. Tradução e prefácio de Frederico Lourenço. São Paulo: Penguin Classics Companhia das Letras, 2013.

HOMERO. Ilíada. Tradução de Christian Werner; colagens de Odires Mlászho. São Paulo: Ubu Editora / SESI-SP Editora, 2018.

KIP, Anna Maria van Erp Taalman. Agamemnon in the Iliad. In: DE JONG, Irene F. J. (ed.). Homer. Critical assessments. Vol. 4. Tradução de B. A. Fasting. London: Routledge, 1999.

KULLMANN, Wolfgang. Ein vorhomerisches Motiv im Iliasproömium. Philologus, v. 99, n. 1-2, p. 167-92, 1955.

MARTIN, Richard. The language of heroes: speech and performance in the Iliad. Ithaca: Cornell University Press, 1989.

MORRISON, James V. Kerostasia, the dictates of fate, and the will of Zeus in the Iliad. Arethusa, v. 40, n. 2, p. 273-96, 1997.

MUELLNER, Leonard. The anger of Achilles. Mênis in Greek epic. Ithaca: Cornell University Press, 2011.

MURNAGHAN, Sheila. Equal honor and future glory: The plan of Zeus in the Iliad. In: ROBERTS, Deborah H., DUNN, Francis M., FOWLER, Don (eds.). Classical closure: reading the end in Greek and Latin literature. Princeton: Princeton University Press, 1997.

NAGY, Gregory. The best of the achaeans. Concepts of the hero in archaic Greek poetry. Baltimore: The John Hopkins University Press, 1999. 
OLIVEIRA, Gustavo Junqueira Duarte. A multidão diante do herói na Ilíada. Dissertação (Mestrado em História Social) - Programa de Pós-graduação em História Social. Faculdade de Filosofia, Letras e Ciências Humanas, Universidade de São Paulo, São Paulo, 2010.

PALMER, Leonard. The Interpretation of Mycenaean Greek texts. Oxford: Oxford University Press, 1963.

PUCCI, Pietro. Honor and Glory in the Iliad. In: PUCCI, Pietro. The Song of the Sirens. Lanham: Rowman \& Littlefield Publishers, 1998, p. 179-230.

PUCCI, Pietro. The Iliad - The Poem of Zeus. Berlin; Boston: De Gruyter, 2018.

PLATO. Republic. Edited and Translated by Christopher Emlyn-Jones, William Preddy. Cambridge: Harvard University Press, 2013.

RABEL, Robert J. Chryses and the opening of the Iliad. The American Journal of Philology, v. 109, n. 4, p. 473-81, 1988.

READY, Jonathan L. Toil and trouble. The acquisition of spoils in the Iliad. Transactions of the American Philological Association, v. 137, n. 1, p. 3-44, 2007.

REDFIELD, James M. Nature and culture in the Iliad. The tragedy of Hector. Chicago: The University of Chicago Press, 1975.

REDFIELD, James M. The Proem of the Iliad: Homer's Art. Classical Philology, v. 74, n. 2, p. $95-110,1979$.

REGO, Julio de Figueiredo Lopes. Alosis/Persis. A poética do saque e destruição de cidades na épica homérica. Tese (Doutorado em Letras Clássicas) - Programa de Pós-graduação em Letras Clássicas. Faculdade de Filosofia, Letras e Ciências Humanas, Universidade de São Paulo, São Paulo, 2020.

ROBBINS, Emmet I. Achilles to Thetis Iliad 1.365-412. In: ROBBINS, Emmet I. Thalia delighting in song. Essays on ancient Greek poetry. Ed. Bonnie MacLachlan. Toronto: University of Toronto Press, 2013, p. 72-87.

ROUSSEAU, Philippe. “L'intrigue de Zeus”. Europe, v. 79, n. 865, p. 120-58, 2001.

SLATKIN, Laura. The power of Thetis and selected essays. Washington, DC: Center for Hellenic Studies, 2011.

TAPLIN, Oliver. Homeric soundings. The shaping of the Iliad. Oxford: Oxford University Press, 1992.

WEIL, Simone. The Iliad or the poem of force. In: DE JONG, Irene (ed.). Homer. Critical assessments. Vol. 3. Transl. M. McCarthy. London: Routledge, 1999.

WERNER, Christian. A astúcia de Aquiles no canto I da Ilíada. Argos, v. 28, p. 93-103, 2004.

YAMAGATA, Naoko. öv $\alpha \xi$ and $\beta \alpha \sigma \imath \lambda \varepsilon u ́ \varsigma$ in Homer. The Classical Quarterly. New series, v. 47, n. 1, p. 1-14, 1997. 